\title{
DESAFIOS DOS ESTAGIÁRIOS EM EDUCAÇÃO FÍSICA NA ELABORAÇÃO DO PLANO DE ENSINO E DE AULA
}

\author{
CHALLENGES OF PHYSICAL EDUCATION INTERNS IN THE LESSON AND TEACHING PLAN \\ ELABORATION
}

\section{RETOS DE LOS ENTRENADOS EN EDUCACIÓN FÍSICA EN LA PREPARACIÓN DEL PLAN DE ENSEÑANZA Y AULA}

Jayane Mara Rosendo Lopes Universidade Estadual do Ceará (UECE) E-mail: jayanemara1@gmail.com

Francisca Feitosa Silva Universidade Regional do Cariri (URCA) E-mail: francisca.feitosa@urca.br

\author{
Antonio Evanildo Cardoso de Medeiros Filho \\ Universidade Estadual do Ceará (UECE) \\ E-mail: evanildofilho17@gmail.com
}

\begin{abstract}
RESUMO
O Estágio Curricular Supervisionado (ECS) é um componente curricular desafiador na formação inicial de professores, sendo o planejamento docente uma ação imprescindível para qualidade das atividades desenvolvidas pelos estagiários. Destarte, o estudo teve como objetivo identificar as dificuldades enfrentadas pelos estagiários do curso de Licenciatura em Educação Física na elaboração do plano de ensino e plano de aula. É um estudo descritivo, exploratório, de abordagem qualitativa com temporalidade transversal. Participaram $55(23,22 \pm 3,87)$ acadêmicos regularmente matriculados no curso de Educação Física de uma Instituição de Ensino Superior (IES) pública do Estado do Ceará, os quais no momento da coleta estavam matriculados na disciplina de Estágio Curricular III (Ensino Fundamental - anos finais) e ECS IV (Ensino Médio). Evidenciamos que na elaboração do plano de ensino a maioria dos estudantes apresenta maior dificuldade (desafiado a muito difícil) na construção da justificativa, objetivo geral, metodologia de ensino e avaliação da aprendizagem. Já na elaboração do plano de aula, esse mesmo resultado ocorre quando no delineamento dos objetivos específicos e critérios de avaliação.
\end{abstract}

PALAVRAS-CHAVE: Estágio Curricular. Formação inicial. Docente.

\section{ABSTRACT}

The Supervised Curricular Internship is a challenging curricular component in the initial training of teachers, being the teaching planning an indispensable action for the quality of the activities developed by the interns. Therefore, the study aimed to identify the difficulties faced by the interns of the degree course in Physical Education in the development of the teaching plan and lesson plan. It is a descriptive, exploratory and crosssectional study, with a qualitative approach, which participated 55 (23.22 3.87$)$ students regularly enrolled in the Physical Education course of a public Higher Education Institution of the State of Ceara. At the time of collection, they were enrolled in subject of Curriculum Internship III (Elementary School - final years) and Curriculum Internship IV (High School). It became evident that in the elaboration of the teaching plan most students present greater difficulty (challenged to very difficult) in the construction of the justification, general objective, teaching methodology and learning evaluation. In the elaboration of the lesson plan, this same result occurs in relation to the delineation of the specific objectives and evaluation criteria.

KEYWORDS: Curricular Internship. Initial training. Teacher. 
La Pasantía Curricular Supervisada (ECS) es un componente curricular desafiante en la formación inicial de docentes, y la planificación docente es una acción fundamental para la calidad de las actividades desarrolladas por los pasantes. Así, el estudio tuvo como objetivo identificar las dificultades que enfrentan los becarios de la Licenciatura en Educación Física en la elaboración del plan docente y plan de lecciones. Se trata de un estudio descriptivo, exploratorio, con abordaje cualitativo con temporalidad transversal. Participaron $55(23,22 \pm 3,87)$ alumnos matriculados habitualmente en el curso de Educación Física de una Institución de Educación Superior (IES) pública en el Estado de Ceará, quienes al momento de la recogida se encontraban matriculados en el Pasantía Curricular III (Docencia Primaria - últimos años) y ECS IV (Bachillerato). Se evidenció que en la elaboración del plan docente, la mayoría de los estudiantes presentan mayor dificultad (desafiada a muy dificil) en la construcción de la justificación, objetivo general, metodología de enseñanza y evaluación del aprendizaje. En la preparación del plan de lección, este mismo resultado ocurre al delinear objetivos especificos y criterios de evaluación.

PALABRAS-CLAVE: Pasantía Curricular; Formación inicial; Profesor.

\section{INTRODUÇÃO}

Problematizamos no presente estudo a atuação dos estudantes de licenciatura em Educação Física no Estágio Curricular Supervisionado (ECS), principalmente, as dificuldades enfrentadas na elaboração do plano de ensino e plano de aula. Assim como Piconez (2012), Pimenta e Lima (2017) e Zabalza (2014), consideramos o ECS como momento indispensável na formação de professores, em que o contato com a comunidade escolar proporciona reflexões sobre a práxis docente.

O ECS é um componente curricular desafiador na formação inicial de professores, sendo o planejamento uma ação imprescindível para qualidade das atividades desenvolvidas (PIMENTA; LIMA, 2017). De acordo com Libâneo (2006), tal prática é uma ação indispensável para qualidade das aulas, pois o exercício de ser professor requer conhecimento e sistematização, configurando o planejamento como o meio em que se fundamenta, organiza e coordena as ações docentes.

Planejar é o ato de organizar um conjunto de atividades na busca de atingir objetivos estabelecidos, trata-se da previsão de ações que poderão ser modificadas em um tempo futuro, sendo realizadas conforme a realidade de cada instituição e modificadas de acordo com o aprendizado dos alunos (ASSIS; BARROS; CARDOSO, 2008).

Nesta perspectiva, para elaboração e reestruturação do planejamento, se faz necessário o diálogo entre estagiários, universidade e escola. Desta maneira, aspectos teóricos e práticos a respeito do planejamento podem ser discutidos de modo a oportunizar a construção de um plano de ensino e de aula condizente com a proposta de estágio, bem como com o contexto de intervenção dos estagiários (BARROS et al., 2015). 
A pouca experiência, autonomia, desconhecimento dos conteúdos, bem como o não entendimento ou desconhecimento da organização escolar também se apresentam como algumas das limitações que podem influenciar diretamente na elaboração e reestruturação do planejamento. No entanto, tais limitações podem ser importantes no processo de formação do estagiário, uma vez que exigem um processo reflexivo e de discussão entre o professor supervisor (do curso), o professor colaborador (da escola) e o estagiário (BARROS et al., 2015).

As dificuldades em planejar a aula são um fator destacado por muitos estagiários, os quais não têm uma compreensão completa do planejamento, encontrando dificuldades para compor o plano e entender sua relevância no exercício de ser professor, tendo bloqueios para aplicá-lo e compreender que o mesmo serve para nortear suas ações no desenvolvimento da aula (REIS; ARAÚJO; BATTINE, 2015).

Neste sentido, o papel do plano de aula é dar um direcionamento nas aulas e permitir que as atividades sejam desenvolvidas de forma intencional, pois a elaboração desse planejamento pode direcionar suas ações numa perspectiva transformadora, buscando atingir objetivos e proporcionando aos alunos aprendizagens significativas (SCHEWTSCHIK, 2017).

Além das dificuldades na elaboração do plano de aula, podemos mencionar outras dificuldades encontradas pelos estagiários, como a escassez ou inexistência de materiais disponíveis para ministrar as aulas. É comum os estagiários, frente a essa realidade, comprar ou até mesmo confeccionar os próprios materiais didáticos uma vez que nem todas as instituições dispõem de materiais. Desse modo, o discente precisa se reinventar para conseguir ministrar aulas, logo, "a introdução de recursos alternativos pode se tornar uma estratégia educacional para lidar com a dependência de alguns materiais" (PEIXOTO; AZEVEDO, 2017, p.17).

Diante do exposto, justificamos a importância deste estudo para futuros estagiários de cursos de licenciatura, em especial de Educação Física, pois eles poderão entender melhor sobre as dificuldades e potencialidades dos atuais acadêmicos do curso de Educação Física ao desenvolver as atribuições da disciplina de Estágio Curricular Supervisionado, especificamente, o plano de ensino e de aula. Somado a isso, o estudo poderá contribuir na reflexão dos professores supervisores e professores colaboradores a respeito dos aspectos teóricos e práticos do planejamento das ações dos estagiários. Desse modo, o estudo teve como objetivo identificar as dificuldades dos estagiários do curso de Educação Física de uma Universidade pública do estado do Ceará na elaboração do plano de ensino e plano de aula. 


\section{MÉTODOS}

O estudo é do tipo descritivo, exploratório, de abordagem qualitativa com temporalidade transversal (PRODANOV; FREITAS, 2013). Teve como participantes 55 $(23,22 \pm 3,87)$ acadêmicos regularmente matriculados no curso de Educação Física da Universidade Regional do Cariri (URCA/UDI). No momento da coleta de dados todos os participantes estavam desenvolvendo o ECS no Ensino Fundamental II ou no Ensino Médio.

Como instrumento de coleta de dados, utilizamos um questionário estruturado pelos autores contendo perguntas abertas e fechadas (com base nos documentos oficiais do estágio do curso investigado). Os dados foram organizados no editor de planilhas Microsoft Excel versão 2016 e analisados por meio de Software SPSS versão 22,00. No que diz respeito às respostas abertas (discursivas), foram interpretadas de modo que extraíssemos as principais respostas para relacioná-las com literatura científica inerente.

Para a realização do estudo consideramos os aspectos éticos defendidos na resolução $n^{\circ}$ 510/2016 do Conselho Nacional de Saúde (CNS) (BRASIL, 2016). Por fim, destacamos que nenhum participante recebeu alguma recompensa, em qualquer espécie, para participação na pesquisa e todos assinaram o Termo de Consentimento Livre e Esclarecido (TCLE).

\section{RESULTADOS E DISCUSSÃO}

Sobre as dificuldades em relação à elaboração do plano de ensino, a maioria dos estudantes considera o nível de dificuldade na construção da justificativa, objetivo geral, metodologia de ensino e avaliação da aprendizagem como desafiado a muito difícil.

Tabela 1 - Nível de dificuldade em relação à elaboração do plano de ensino.

\begin{tabular}{llccccc}
\hline \multicolumn{1}{c}{ Subitens } & 1 & 2 & 3 & 4 & 5 \\
\hline & & \multicolumn{4}{c}{$\%$} & \\
Q3.1 & Disciplina & 61,8 & 21,8 & 12,7 & 1,8 & 1,8 \\
Q3.2 & Justificativa & 18,2 & 29,1 & 36,4 & 7,3 & 9,1 \\
Q3.3 & Objetivo Geral & 10,9 & 32,7 & 36,4 & 14,5 & 5,5 \\
Q3.4 & Conteúdo programático & 36,4 & 27,3 & 23,6 & 12,7 & 0,0 \\
Q3.5 & Cronograma & 38,2 & 29,1 & 21,8 & 10,9 & 0,0 \\
Q3.6 & Metodologia de ensino & 9,1 & 32,7 & 38,2 & 12,7 & 7,3 \\
Q3.7 & Avaliação & 14,5 & 23,6 & 49,1 & 5,5 & 7,3 \\
Q3.8 & Bibliografia básica & 36,4 & 40,0 & 18,2 & 3,6 & 1,8 \\
\hline
\end{tabular}

Fonte: Elaboração Própria

Legenda: 1 - Fácil; 2 - Moderado; 3 - Desafiado; 4 - Difícil; 5 - Muito difícil

A prática de ensino revela situações complexas que influenciam diretamente na elaboração do planejamento. Uma dessas dificuldades é a adaptação dos conteúdos estudados 
durante a graduação à prática docente (GONDIM; SEGATTO, 2015). Deste modo, o plano de ensino é uma forma de preparação do professor que busca desenvolver suas ações docentes no decorrer do ano ou do semestre (SPUDEIT, 2014).

Referindo-se à elaboração do planejamento, Reis, Araújo e Battini (2015) relatam que é uma fase de divergências de ideias vivenciadas pelos estagiários, momento em que estes expõem medo, falta de segurança e dúvidas; geralmente a primeira resposta é dizer que não sabem fazer, além disso, tendem a reproduzir modelos de planos com os quais tiveram contato.

Quanto à metodologia, parte integrante do plano de ensino, trata-se das estratégias de ensino, recursos didáticos, tempo decorrido para o desenvolvimento das atividades e outros aspectos necessários para atingir o objetivo de ensino proposto. Destacamos que esses aspectos são mais detalhados e específicos no plano de aula, sendo apresentados de modo geral no plano de ensino. No Quadro 1, apresentamos as principais respostas imprimidas pelos estagiários quanto às dificuldades para desenvolver a metodologia de ensino.

Quadro 1 - Dificuldades dos estagiários para desenvolver a metodologia a ser usada no plano de ensino.

\begin{tabular}{|c|c|}
\hline E 5 & $\begin{array}{l}\text {..as várias formas de contemplação dos conteúdos ainda parece ser novidade, precisando } \\
\text { e um aprofundamento maior para compreender" }\end{array}$ \\
\hline E 9 & $\begin{array}{l}\text {...Principalmente na metodologia de ensino, a qual muitas vezes é alterado no decorrer } \\
\text { as aulas" }\end{array}$ \\
\hline & “...por que isso foi explicado de maneira superficial durante o conteúdo de didática” \\
\hline E 51 & $\begin{array}{l}\text { "...na maioria das vezes ou quase sempre, é necessário levar uma metodologia de acordo } \\
\text { com cada turma, ou seja, procurar um método e aplicar sempre com a necessidade do } \\
\text { aluno" }\end{array}$ \\
\hline E 52 & $\begin{array}{l}\text { "...de acordo com o ensino exige metodologias diferentes, porém a metodologia não } \\
\text { contempla as ideias que o professor pretende repassar para cada turma, dificultando a } \\
\text { escolha da mesma" }\end{array}$ \\
\hline E 53 & $\begin{array}{l}\text { neu entendimento ainda não ficou claro o que é possível colocar como metodologia } \\
\text { o sempre confundindo com os diversos tipos de abordagem" }\end{array}$ \\
\hline & $\begin{array}{l}\text { "...pois acabo ficando em dúvida na qual se encaixa melhor com o estágio em que } \\
\text { estamos" }\end{array}$ \\
\hline
\end{tabular}

Fonte: Elaboração Própria.

Constatamos que os discentes têm várias divergências para desenvolver essa seção no plano de ensino: sentem a necessidade de mais aprofundamento nas orientações, sofrem com alterações dentro do plano no decorrer do estágio, relatam que foi explicado de maneira superficial na disciplina de didática ou que os alunos têm um aprendizado e desenvolvimento diferente, até mesmo que as turmas necessitam de uma metodologia diferente. 
Para Libâneo (2013) planejar é uma função que cabe ao professor desenvolver junto ao aluno e que abrange não somente atividades de forma organizada e coordenadas diante dos objetivos, mas também a sua correção e adaptação durante o processo de ensino. Consideramos que os estagiários precisam compreender que o plano elaborado para todo o estágio pode ser modificado de acordo com a realidade vivenciada, desde que a carga horária e os objetivos sejam atingidos.

No que diz respeito aos objetivos de ensino, estes devem considerar os resultados que se espera dos alunos após o processo educativo. Este item também dispõe da relação direta com os métodos de avaliação, que precisam observar se esses objetivos foram alcançados de maneira considerável.

Sendo assim, as dificuldades relatadas pelos estagiários para desenvolver os objetivos do plano de ensino são diversas. Como exemplo, “...dificuldade em fazer objetivos que englobe tudo" (E4) ou seja todo conteúdo a ser repassado nas regências; “...pois acaba confundindo com a justificativa" sendo estes pontos diferentes mas obrigatórios no plano de ensino (E6); “diferenciação dos verbos, um pouco confuso", sendo estes parte obrigatória no plano de ensino (E14).

Frente a essas respostas, podemos observar que os estagiários explanam ter dificuldades para desenvolver os objetivos para todo o período da disciplina de ECS, outros confundem os objetivos com a justificativa, não sabendo diferenciá-los, nem tampouco os verbos. Diante disso, Cardoso e Silva (2008) relata que é importante o docente encarregado da disciplina, discutir em sala sobre os aspectos teóricos e práticos que norteiam o plano de ensino.

No plano de ensino é necessário contemplar a avaliação da aprendizagem dos alunos, a saber: avaliação diagnóstica, formativa e somativa (MAGALHÃES JUNIOR, 2015). Especificamente, a diagnóstica é utilizada pelo professor para verificar os conhecimentos prévios dos alunos sobre uma determinada temática. Já a avaliação formativa é utilizada com a finalidade de analisar a aprendizagem do aluno durante todo o período de ensino. Quanto à avaliação somativa, esta é utilizada para avaliar a evolução dos alunos no fim do período letivo.

Destacamos os seguintes argumentos dos estagiários em relação às dificuldades de entender qual tipo de avaliação utilizar no plano de ensino: “...identificar quais os métodos mais adequados para avaliar o aluno” (E11); “...por ter que pensar meios para perceber se o aluno está aprendendo o conteúdo, não com o intuito de reproduzir gestos técnicos, em que não é o 
intuito" (E23); “...que não temos oportunidade de conhecer bem os alunos e a realidade inserida" (E49).

Podemos observar que há relatos de estagiários que não conseguem identificar quais os métodos para avaliação são mais adequados ao aluno diante de suas regências, podendo prejudicar o desenvolvimento e aprendizado dos mesmos. Além disso, há relatos de dificuldades por não conhecerem a realidade dos estudantes, mesmo com a fase de observação dos alunos, e orientações com professor colaborador e da instituição. Os estagiários alegam ser curto o tempo em que passam dentro das instituições.

Após o planejamento geral das regências que funciona como um guia para o professor estagiário durante todo processo de ensino, vem o plano de aula que também faz parte do planejamento do estagiário. O plano de aula dar suporte ao estagiário durante cada regência de classe. Contudo, há quem considere a elaboração do plano de aula um procedimento difícil (TREVISAN, ANTUNES; GONZÁLES, 2017).

Santos e Almeida (2015), afirmam que a experiência no período do ECS é parte essencial que dar suporte, constitui e capacita o profissional de forma que ele se sinta mais preparado para atuar no trabalho docente e seja capaz de resolver eventos adversos em sua práxis docente. Além disso, o estagiário pode ter uma melhor compreensão da construção do plano de aula, entendendo melhor a complexidade na elaboração desse plano e assimilando com mais facilidade o conteúdo a ser ministrado, aprendendo também a enfrentar a rotina escolar.

No que concerne à percepção dos estagiários em relação ao nível de dificuldade de cada seção da elaboração do plano de aula, a maioria considera o nível de dificuldade na construção dos objetivos de aprendizagem e critérios de avaliação como desafiado a muito difícil. Na Tabela 2 estão expostos os níveis de dificuldade com relação a cada etapa da construção.

Tabela 2. Nível de dificuldade em relação à elaboração do plano de aula.

\begin{tabular}{|c|c|c|c|c|c|c|}
\hline \multicolumn{2}{|r|}{ Subitens } & \multirow{2}{*}{\multicolumn{3}{|c|}{$\frac{2}{\%}$}} & \multirow[t]{2}{*}{4} & \multirow[t]{2}{*}{5} \\
\hline & & & & & & \\
\hline Q1.1 & Conteúdo de Ensino & 43,6 & 36,4 & 16,4 & 1,8 & 1,8 \\
\hline Q1.2 & Situação Didática & 29,1 & 32,7 & 23,6 & 12,7 & 1,8 \\
\hline Q1.3 & Objetivos Específicos & 9,1 & 20,0 & 38,2 & 27,3 & 5,5 \\
\hline Q1.4 & Critérios de Avaliação & 16,4 & 30,9 & 29,1 & 20,0 & 3,6 \\
\hline
\end{tabular}




\begin{tabular}{lllllll}
\hline Q1.5 & Estratégias e Instru. de Avaliação & 20,0 & 30,9 & 36,4 & 7,3 & 5,5 \\
Q1.6 & Recursos Didáticos & 41,8 & 23,6 & 20,0 & 10,9 & 3,6 \\
Q1.7 & Descrições das atividades & 54,5 & 23,6 & 12,7 & 1,8 & 7,3 \\
Q1.8 & Referências & 47,3 & 27,3 & 14,5 & 7,3 & 3,6 \\
\hline
\end{tabular}

Fonte: Elaboração própria

Legenda: 1 - Fácil; 2 - Moderado; 3 - Desafiado; 4 - Difícil; 5 - Muito difícil.

O plano de aula requer do professor uma maior dedicação, pois este necessita estudar quais conteúdos irão atender às necessidades de cada turma. Diante disso, "o plano de aula pode ser definido como a previsão dos conteúdos e atividades de uma ou de várias aulas que compõem uma disciplina ou unidade de estudo. É a sequência de tudo o que vai ser desenvolvido em um dia letivo" (DE GOÉS, 2015, p. 5).

A falta de planejamento pode acarretar problemas na qualidade do ensino, tornando as regências monótonas e cheias de improvisos. Deste modo, os estagiários podem não obter resultados desejados nas suas regências de classe, contribuindo para um desinteresse pela área educacional.

Pesquisa realizada com monitores de um projeto que buscava conhecer as dificuldades dos mesmos ao construir o plano de aula evidenciou impasse em desenvolver educativos e pensar em atividades lúdicas que alcançasse os objetivos propostos para os alunos (ANDREOLLI et al., 2015).

Elaborar planos de aula é uma das dificuldades encontradas pelos estudantes durante o desenvolvimento do estágio, pois requer criatividade de forma que atenda aos objetivos educacionais e às demandas do contexto social. Como podemos observar no Quadro 2, os estagiários têm dificuldades em entender quais objetivos são voltados para o aluno e quais são voltados para o professor, assim como também abordar as dimensões: conceitual, procedimental e atitudinal no plano de aula. Outra dificuldade é para ligar os verbos ao conteúdo a ser ensinado. Sugerimos a leitura do Quadro abaixo para identificação de outras dificuldades alegadas pelos estagiários ao elaborar o plano de aula.

Quadro 2. Dificuldades dos estagiários na elaboração dos objetivos do plano de aula.

\begin{tabular}{|c|l|}
\hline E 6 & “...é confuso diferenciar os objetivos dos alunos e do professor" \\
\hline E 10 & “...por que não entendo quando é referente ao professor e ao aluno" \\
\hline E 11 & $\begin{array}{l}\text { “...principalmente em relação a colocação dos verbos em conceitual, procedimental e } \\
\text { atitudinal” }\end{array}$ \\
\hline E 29 & “...devido as dimensões conceituais, procedimentais e atitudinais" \\
\hline E 35 & “...em abordar as três dimensões" \\
\hline
\end{tabular}




Revista Triângulo
ISSN 2175-1609
\begin{tabular}{|l|l|}
\hline E 14 & "...diferenciação dos verbos, as vezes confunde" \\
\hline E 15 & "...por que se torna difícil pensar nos objetivos para cada conteúdo" \\
\hline E 16 & "... conciliação com o conteúdo" \\
\hline E 33 & $\begin{array}{l}\text { "...dependendo do conteúdo, consigo imaginar o que as atividades irão proporcionar, mas } \\
\text { na hora de passar para o papel sinto um bloqueio" }\end{array}$ \\
\hline E 55 & "...devido as dificuldades para ligar um objetivo ao outro" \\
\hline
\end{tabular}

Fonte: Elaboração Própria.

O planejamento funciona como um guia para o professor ministrar sua aula, uma vez que é elaborado com antecedência à regência de classe. Diante disso, o desenvolvimento de um plano de aula, onde são traçados, dentre outros aspectos, os objetivos, conteúdos e recursos metodológicos, pode permitir ao professor observar, fichar e verificar o processo de aprendizagem dos estudantes (RICHTER, 2009). É oportuno ressaltar que "o ato de avaliar é um processo contínuo que deve ocorrer nos mais diferentes momentos do trabalho e não apenas em um período específico" (PEDREIRA et al., 2013, p. 5).

Dentre os argumentos dos estagiários em relação às dificuldades para utilizar o critério ou estratégia de avaliação no plano de aula para as regências, destacamos: “...dificuldade em pensar uma avaliação de acordo com o plano de ensino e baseá-lo em aula por aula” (E23); “...é difícil abordar uma estratégia que beneficie todos" (E44); “...devido a complexidade em avaliar os conhecimentos dos alunos de forma adequada e ampla" (E50).

A avaliação faz parte do processo de aprendizagem do aluno, pois ajuda o docente a identificar em quais níveis de aprendizagem o aluno se encontra e, consequentemente, tomar decisões (RIBEIRO et al., 2019). Corroborando, Venâncio e Sanches Neto (2019) relatam que o método de avaliação é imprescindível para o desenvolvimento do aluno, contribuindo não só para a autonomia do sujeito de forma crítica, mas também que este seja crítico de suas próprias ações e as do outro.

Aproximando-nos do final dessa discussão, gostaríamos de destacar que os estagiários apontaram algumas dificuldades em relação à escassez de materiais disponíveis nas instituições para as regências de classe. Como exemplo: “...muitas vezes não era possível passar determinada atividade para os alunos por não termos os materiais necessários” (E19); “...mesmo tendo o dever e obrigação de criar ou adaptar alguns materiais para tais atividades, muitas vezes precisamos custear com isso e nem sempre podemos pagar" (E51).

Diante disso, Canestraro, Zulai e Kogut (2008) ressaltam que é preciso munir as escolas com materiais necessários, assim como também preservar as quadras de esportes com 
aparelhos, pois estes insumos fazem parte dos materiais didáticos utilizados no processo de ensino-aprendizagem, além de poder incentivar a participação dos alunos nas aulas.

A partir dos dados e discussões apresentas acima, são notórias as dificuldades dos discentes frente às experiências no ECS no que diz respeito à elaboração do plano de ensino e plano de aula. Desse modo, fica necessário o diálogo entre as instituições formadoras, instituições recebedoras dos estagiários e os próprios estagiários para mudança dessa realidade.

\section{CONSIDERAÇÕES FINAIS}

Evidenciamos que na elaboração do plano de ensino a maioria dos estudantes apontam maior dificuldade (desafiado a muito difícil) na construção da justificativa, objetivo geral, metodologia de ensino e avaliação da aprendizagem. Já na elaboração do plano de aula, este mesmo resultado ocorre no delineamento dos objetivos específicos e critérios de avaliação.

A partir desses resultados alertamos a necessidade do diálogo entre os professores das disciplinas de graduação, professores colaboradores (da escola) e estagiários para traçar estratégias que tenha como finalidade promover conhecimentos necessários aos estagiários para melhor desempenhar seus planejamentos, consequentemente, as regências de classe.

Ao analisarmos a bibliografia, identificamos que a temática proposta nesse estudo pouco vem sendo explorada por profissionais da área. Dessa maneira, sugerimos futuras pesquisas que busquem uma melhor compreensão, por meio de entrevistas e grupos focais, das dificuldades dos estagiários e dos docentes supervisores acerca do planejamento de ensino e de aula, bem como a elaboração de outras pesquisas sobre essa temática em outras instituições de ensino, tanto pública, quanto privada, como em outras regiões do país.

\section{REFERÊNCIAS}

ANDREOLLI, M. et al. A experiência prévia de monitores do projeto de extensão "atividades ginásticas": facilidades e dificuldades. CONGRESSO DE EXTENSÃO UNIVERSITÁRIA DA UNESP. 8. 2015. São Paulo. Anais [...]. São Paulo. CEU. 2015. Disponível em: https://repositorio.unesp.br/handle/11449/142666. Acesso em: 21 set. 2020.

ASSIS, R.M.; BARROS, M. O.; CARDOSO, N. S. PLANEJAMENTO DE ENSINO: algumas sistematizações. Revista Eletrônica de Educação do Curso de Pedagogia Campus Jataí da Universidade Federal de Goiás. v. 1, n. 4, 2008. DOI: 10.5216/rir.v1i4.214. 
BARROS, N. F. et al. Estágio supervisionado na educação física: um relato da prática docente no ensino fundamental. CONGRESSO NACIONAL DE EDUCAÇÃO. 3. 2015. João Pessoa. Anais [...]. João Pessoa. CONEDU. 2015.

BARROS, N. F. et al. Estágio supervisionado na educação física: um relato da prática docente no ensino fundamental. CONGRESSO NACIONAL DE EDUCAÇÃO. 3. op. cit, 2015. João Pessoa. Anais [...]. João Pessoa. CONEDU, 2015.

BRASIL. Conselho Nacional de Saúde. 2016. Resolução n 510/2016. Brasília. 2016. Disponível em: <http://conselho.saude.gov.br/resolocoes/2016/reso510.pdf>. Acesso em: 12 maio. 2020.

CANESTRARO, J. F.; ZULAI, L. C.; KOGUT, M. C. Principais dificuldades que o professor de educação física enfrenta no processo ensino-aprendizagem do ensino fundamental e sua influência no trabalho escolar. Paraná. 2008. Disponível em: https://educere.bruc.com.br/arquivo/pdf2008/872_401.pdf. Acesso em: 21 set. 2020.

CARDOSO, M. Y. N. P.; SILVA, A. C. C. Metodologia para construção de materiais didáticos na EAD: do plano de ensino ao roteiro de tutoria. Maio. 2008. . Disponível em: http://www.abed.org.br/congresso2008/tc/1152008220039.pdf. Acesso em: 21 set. 2020.

DE GOÉS, F. S. N. et al. Plano de aula: apoio e fundamentos para prática docente. Livro eletrônico. Ribeirão Preto- SP. 2015. Disponível em:

http://www.eerp.usp.br/ebooks/planodeaula/pdf/1Planodeaula.pdf. Acesso em: 21 set. 2020.

GONDIM, M. S. C.; SEGATTO, M. S. O estágio supervisionado e suas dificuldades na visão de estagiários em licenciatura em Química do IQUFU. ENCONTRO NACIONAL DE PESQUISA EM EDUCAÇÃO EM CIÊNCIAS. 10. 2015. Águas de Lindóia. Anais [...]. Águas de Lindóia/ SP. ENPEC. Nov. 2015. Disponível em: http://www.abrapecnet.org.br/enpec/x-enpec/anais2015/resumos/R0917-1.PDF. Acesso em: 21 set. 2020.

LIBÂNEO, J. C. Didática. São Paulo, Cortez. 2006.

LIBÂNEO, J. C. O Planejamento Escolar. Jul. 2013. Disponível em: https://edisciplinas.usp.br/pluginfile.php/4452090/mod resource/content $/ 2 /$ Planejamento $\% 20$ \%20Lib\%C3\%A2neo.pdf . Acesso em: 10 jun. 2020.

MAGALHÃES JUNIOR, A. G. Especialização em EAD: Avaliação na Educação a Distância. Editora da Universidade Estadual do Ceará - EdUECE. Fortaleza. 2015.

PEDREIRA, H. P. S. et al. Métodos avaliativos: um olhar reflexivo sobre a prática docente nas avaliações escolares. CONGRESSO NACIONAL DE EDUCAÇÃO. 11. 2013. Curitiba. Anais [...]. Curitiba. EDUCERE. 2013. Disponível em:

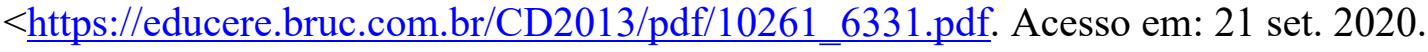


PEIXOTO, R. P.; AZEVEDO, I. O. S. Materiais alternativos nas aulas de ducação física: possibilidades e desafios. Temas em Educação Física Escolar. v. 2, n. 1, p. 15-29, Rio de Janeiro, jan./Jun. 2017. DOI: http://dx.doi.org/10.33025/tefe.v2i1.714.

PICONEZ, S. (Org) A prática de ensino e o estágio supervisionado. 24 ed. - Campinas, SP: Papirus, 2012.

PIMENTA, S. G.; LIMA, M. S. L. Estágio e Docência. 8. ed. São Paulo: Cortez, 2017. 310p.

PRODANOV, C. C.; FREITAS, E. C. METODOLOGIA DO TRABALHO CIENTÍFICO: Métodos e Técnicas da Pesquisa e do Trabalho Acadêmico. $2^{\circ}$ ed. Novo Hamburgo/RS. Universidade Freevale. 2013. Disponpivel em: http://www.feevale.br/Comum/midias/8807f05a-14d0-4d5b-b1ad-1538f3aef538/Ebook\%20Metodologia\%20do\%20Trabalho\%20Cientifico.pdf. Acesso em: 21 set. 2020.

REIS, S. R.; ARAÚJO, R. N.; BATTINI, O. O estágio supervisionado e a construção do conceito de planejamento. CONGRESSO NACIONAL DE EDUCAÇÃO. 7. 2015. Paraná. Anais [...]. Paraná: EDUCERE. 2015. Disponpivel em: https://educere.bruc.com.br/arquivo/pdf2015/18739 9419.pdf. Acesso em: 21 set. 2020.

RIBEIRO, F. S. et al. Avaliação escolar e seus métodos: um estudo de caso na Escola Garcia Garrido Firmino em Peixoto de Azevedo. Nativa-Revista de Ciências Sociais do Norte de Mato Grosso. v. 8, n. 1, 2019.

RICHTER, A. C. Dos lugares do esporte nas aulas de educação física: algumas possibilidades de intervenção pedagógica. Cadernos de Formação RBCE. p. 43-56, Florianópolis. Set. 2009. Disponível em: http://revista.cbce.org.br/index.php/cadernos/article/view/931. Acesso em: 21 set. 2020.

SANTOS, W. L.; ALMEIDA, M. S. Perspectivas e desafios da prática de estágio supervisionado no curso de pedagogia. Revista Científica da FASETE. Bahia. 2015. Disponível em:

https://www.unirios.edu.br/revistarios/media/revistas/2015/9/perspectivas_e_desafios_da_prat ica de estagio supervisionado_no_curso_de pedagogia.pdf. Acesso em: 21 set. 2020.

SCHEWTSCHIK, A. O planejamento de aula: um instrumento de garantia de aprendizagem. CONGRESSO NACIONAL DE EDUCAÇÃO. 8. 2017. Anais [...]. EDUCERE. 2017. Disponível em: https://educere.bruc.com.br/arquivo/pdf2017/26724_13673.pdf. Acesso em: 21 set. 2020.

SPUDEIT, D. Elaboração do plano de ensino e plano de aula. Universidade Federal do Rio de Janeiro- UNIRIO. Rio de Janeiro. Fev. 2014. Disponível em:

http://www.ppgd.unirio.br/unirio/cchs/eb/ELABORAODOPLANODEENSINOEDOPLANO DEAULA.pdf. Acesso em: 21 set. 2020.

TREVISAN, K. I.; ANTUNES, F. R.; GONZÁLEZ, F. J. Fatores que interferem no planejamento escolar: dificuldades de uma docente da rede básica de ensino. SALÃO DO CONHECIMENTO: A MATEMÁTICA ESTÁ EM TUDO. 25. 2017. Rio Grande do Sul. 
Anais [...]. Santa Rosa- RS. UNIJUI. 2017. Disponível em:

https://publicacoeseventos.unijui.edu.br/index.php/salaoconhecimento/article/view/7961. Acesso em: 21 set. 2020.

VENÂNCIO, L.; SANCHES NETO, L. Instrumentos e critérios no processo de avaliação em Educação Física escolar: "Errar é humano", mas é fonte de aprendizagem. Rev. Est. e Pesq. em Educação. v. 21, n. 1, p. 58-73, Fortaleza-CE. Jan/Jun. 2019.

DOI: https://doi.org/10.34019/1984-5499.2019.v21.19136.

ZABALZA, M. A. O estágio e as práticas em contextos profissionais na formação universitária. 1. ed. São Paulo: Editora Cortez, 2014. p.327. 